\title{
Characterization and Identification of Coagulase-negative, Heat-stable Deoxyribonuclease-positive Staphylococci
}

\author{
By JANE L. GRAMOLI AND BRIAN J. WILKINSON \\ Departments of Medicine and Microbiology, University of Minnesota, \\ Mayo Memorial Building, Minneapolis, Minnesota 55455, U.S.A.
}

(Received 17 November 1977)

\begin{abstract}
Various characteristics of 13 coagulase-negative, weakly heat-stable deoxyribonucleasepositive staphylococci from human, veterinary and food sources were determined in an effort to identify them. Nine of the isolates were identified as coagulase-negative Staphylococcus aureus (2), Staphylococcus xylosus (2), Staphylococcus simulans (3), Staphylococcus capitis (1) and Staphylococcus sciuri subsp. lentus (1); the other four isolates, from food and veterinary sources, could not be identified as currently accepted or proposed species. Teichoic acid and peptidoglycan compositions were used as key taxonomic characteristics. The determination of heat-stable deoxyribonuclease activity can be useful to detect coagulase-negative $S$. aureus strains. However, this activity also appears to. be present in strains of other staphylococcal species.
\end{abstract}

\section{INTRODUCTION}

Currently, the most widely accepted staphylococcal species are Staphylococcus aureus, Staphylococcus epidermidis and Staphylococcus saprophyticus. Coagulase production is a key characteristic of $S$. aureus and most pathogenic and toxigenic staphylococci are confined to this species. The ability of an organism to produce heat-stable deoxyribonuclease correlates well with $S$. aureus (Victor et al., 1969), and has been determined simultaneously with coagulase in staphylococcal identification (Barry, Lachica \& Atchison, 1973). Staphylococcus epidermidis and $S$. saprophyticus are considered to be negative in these two tests.

Several authors have described a relatively rare group of coagulase-negative, heat-stable deoxyribonuclease-positive staphylococci (Victor et al., 1969; Barry et al., 1973; Jasper, 1973; Lotter \& Genigeorgis, 1975; Rayman et al., 1975) of uncertain identity. In this investigation, 13 such organisms were encountered on screening 197 isolates received from a variety of sources as 'atypical staphylococci'. The remainder of the organisms were either positive or negative in both tests except for one which was coagulase-positive and heat-stable deoxyribonuclease-negative; these organisms were not studied further. The purpose of the work described here was to characterize the 13 coagulase-negative, heatstable deoxyribonuclease-positive organisms to see if they had more characteristics in common with $S$. aureus or with coagulase-negative strains. Particular attention was paid to the cell-wall teichoic acid type and the peptidoglycan composition.

The studies revealed that two of the organisms were $S$. aureus strains that failed to produce coagulase, seven were identified by the criteria described for coagulase-negative staphylococci (Kloos, Schliefer \& Noble, 1976) but four organisms could not be classified by any of the schemes available, though they were undoubtedly staphylococci. 


\section{METHODS}

Taxonomic schemes. The schemes used for evaluation of the organisms were those of Baird-Parker (1974), which recognize $S$. aureus, $S$. epidermidis and $S$. saprophyticus plus the $S$. aureus biotype characteristics described by Hájek \& Maršálek (1971). For further resolution, the coagulase-negative strains were evaluated according to the criteria of Kloos \& Schliefer (1975a, b), Kloos et al. (1976), Kloos, Schliefer \& Smith (1976) and Schliefer \& Kloos (1975), as recommended by the International Subcommittee (1976).

Cultures. The test organisms, kindly provided by workers at several institutions, were from a variety of sources (Table 1). Isolates were maintained on BBL Brain Heart Infusion Agar (BHI agar) at $4{ }^{\circ} \mathrm{C}$. Unless stated otherwise, all inocula were derived from overnight growth in $10 \mathrm{ml}$ BBL Brain Heart Infusion Broth (BHI broth), and tests were performed at $37^{\circ} \mathrm{C}$.

Cellular and colonial morphology. Gram-stained preparations were examined under a light microscope for colour reaction, cell size and arrangement. Motility was determined with hanging drop preparations observed under a phase-contrast microscope. Colonial morphology was observed after growth on $\mathrm{P}$ agar for $5 \mathrm{~d}$ (Kloos, Tornabene \& Schliefer, 1974).

Respiratory system. Catalase production (Baird-Parker, 1963) and a modified benzidine test (Deibel \& Evans, 1960) were determined simultaneously after overnight growth on $1 \%(\mathrm{w} / \mathrm{v})$ glucose agar. Oxidase was assayed as described by Kovacs (1956).

Growth characteristics. Growth at $45^{\circ} \mathrm{C}$ was determined after 24 and $48 \mathrm{~h}$, and anaerobic growth in thioglycollate broth was determined according to Evans \& Kloos (1972). Growth in the presence of lysozyme and salt tolerance were determined by the methods of Kloos et al. (1974). Growth in crystal violet was determined by streaking cultures on Crystal Violet Agar (Difco) followed by examination after 24 and $48 \mathrm{~h}$.

Enzymic activities. Coagulase production was determined by the tube assay using fresh rabbit (Difco), porcine (gift of Geo. A. Hormel Co., Austin, Minnesota, U.S.A.) and human plasmas. Rabbit plasma was used as recommended by the manufacturer; porcine plasma was used undiluted. Human plasma was prepared from fresh pooled blood (gift of Donor Room, University of Minnesota Hospitals, Minneapolis, Minnesota, U.S.A.) collected in EDTA Vacutainers. Blood was centrifuged to remove the red cells, diluted 1: 3 with distilled water, filter-sterilized and frozen in sterile test-tubes prior to use. The tube assay was performed by adding $0.25 \mathrm{ml} \mathrm{BHI}$ broth culture to $0.5 \mathrm{ml}$ plasma in sterile, capped $12 \times 75 \mathrm{~mm}$ tubes which were examined for clotting after 1, 2, 3, 4 and $24 \mathrm{~h}$, and scored as 0 to $4+$ (Turner \& Schwartz, 1958).

Clumping factor was determined with rabbit plasma (Difco) according to the manufacturer's instructions.

Fibrinolysin was determined by a plate method (Hinton \& Orr, 1957) using $15 \%$ undiluted, filter-sterilized rabbit plasma incorporated into tempered BHI agar. Soy Bean Trypsin Inhibitor (1\%, w/v; Sigma) was used to distinguish fibrinolysin from other proteases.

Organisms were assayed for both heat-labile and heat-stable deoxyribonucleases using the microslide technique (Lachica, Genigeorgis \& Hoepich, 1971). Cultures were grown statically in BHI broth (overnight) or with aeration $\left(50 \mathrm{ml}\right.$ in $250 \mathrm{ml}$ flasks shaken at $250 \mathrm{rev} . \mathrm{min}^{-1}$ for $24 \mathrm{~h}$ ). Deoxyribonuclease was also assayed by the method of Barry et al. (1973) using larger samples.

The ability to produce haemolysins was determined on BBL Trypticase Soy Agar containing sheep blood. Plates were incubated for $24 \mathrm{~h}$, examined for clearing and then refrigerated overnight at $4{ }^{\circ} \mathrm{C}$ to demonstrate the 'hot-cold' phenomenon of $\beta$-haemolysin.

Nitrate reductase was determined after aerobic growth for $2 \mathrm{~d}$ in Nitrate Broth (Difco). After incubation, $1 \mathrm{ml}$ broth was removed and tested for nitrate reduction by the addition of 5 drops each of sulphanilic acid and $\alpha$-naphthylamine (Cowan \& Steel, 1965).

Phosphatase activity was determined by the method of Pennock \& Huddy (1967), using a loopful of overnight culture from $\mathbf{P}$ agar as inoculum.

'Lysozyme' production (bacteriolytic activity) was determined by a plate method. Micrococcus luteus (1 litre) was grown aerobically for $24 \mathrm{~h}$ in the medium of Salton \& Freer (1965) at $30^{\circ} \mathrm{C}$. Cells were harvested by centrifugation $(16313 \mathrm{~g}, 5 \mathrm{~min})$, washed in water and resuspended in $250 \mathrm{ml}$ rehydrated BHI agar. The medium was autoclaved and plates were poured with tempered medium. Cultures were spotted on to the surface and incubated and examined after 24 and $48 \mathrm{~h}$. Any clearing in the medium was considered to be a positive reaction.

Tellurite reductase was observed after growth for 24 and $48 \mathrm{~h}$ on Baird-Parker Agar (Difco). Black or grey colonies were considered strong or weak reactions respectively.

Carbohydrate utilization. The fermentation of glucose and mannitol was determined by the method recommended by the International Subcommittee (1965). Aerobic utilization and acid production from carbohydrates was determined by streaking cultures on Purple Agar Base supplemented with $1 \%$ (w/v) filter-sterilized sugar as described by Kloos et al. (1974). 


\begin{tabular}{ll} 
Strain & \multicolumn{1}{c}{ Table 1. Origin } \\
$\begin{array}{l}\text { Test organisms } \\
\text { RB-8 }\end{array}$ & Origin \\
RB-11 & Equine hock joint \\
FB-1 & Feline urine \\
FB-2 & Turkey bone \\
ML-26 & Turkey joint \\
ML-55 & Human urine \\
LH-A3 & Human urine \\
LH-A12 & Human urine \\
FDA-R75 & Human urine \\
& Nose/throat of \\
& healthy human \\
TPC-1 & \\
TPC-2 & Wholesome food \\
TPC-3 & Wholesome food \\
TPC-Armour & Wholesome food \\
Control organisms & Wholesome food \\
Staphylococcu aureus ATCC 10832 \\
Staphylococcus epidermidis ATCC 14990 \\
Staphylococcus saprophyticus ATCC 15303 \\
S. aureus strain H & \\
\end{tabular}

\section{Micrococcus luteus}

\section{Table 1. Origin and source of organisms used}

\section{Source}

Remi Brooks, Dept Veterinary Medicine, University of Minnesota, St Paul, Minnesota, U.S.A.

Fern Bates, Dept Veterinary Medicine, University of Minnesota, St Paul

Marlys Lund, Dept Laboratory Medicine, University of Minnesota, Minneapolis

Louise Hoffher, Dept Laboratory Medicine, University of Minnesota, Minneapolis

Reginald Bennett, Microbiology Division, Food and Drug Administration, Washington, D.C., U.S.A.

William Sperber, The Pillsbury Co., Minneapolis

The production of acetoin and final $\mathrm{pH}$ after growth in $2 \%$ glucose broth was determined by the method of Baird-Parker (1963). Acetoin was detected by the modified Voges-Proskauer test (Barritt, 1936).

Wall composition. The presence of glycine cross-bridges in the cell wall was determined indirectly by measuring the susceptibility to lysis by lysostaphin. Cultures were grown overnight in $5 \mathrm{ml}$ BHI broth to which $0.1 \mathrm{ml}$ lysostaphin solution $\left(1.25 \mathrm{mg} \mathrm{ml}^{-1}\right)$ was added. Absorbance was measured initially and after incubation for $2 \mathrm{~h}$ at $37^{\circ} \mathrm{C}$. The organism was considered to be susceptible if a reduction in turbidity greater than $60 \%$ after $2 \mathrm{~h}$ was attained.

Walls were isolated from organisms grown in 1 litre culture for 18 to $24 \mathrm{~h}$ at $37^{\circ} \mathrm{C}$ with shaking (250 rev. min $^{-1}$ ) in $\mathbf{P}$ medium constituted with Difco Yeast Extract and Difco Bacto Peptone and supplemented with $0.3 \%(w / v) \mathrm{K}_{2} \mathrm{HPO}_{4}$. Schliefer, Hammes \& Kandler (1976) have shown that the original $\mathrm{P}$ medium yields walls with low glycine contents. Cells were washed once in water and then broken with glass beads $(0 \cdot 10$ to $0.11 \mathrm{~mm}$ diam.; VWR Scientific, Denver, Colorado, U.S.A.) by shaking for $20 \mathrm{~min}$ at top speed in a Vibrogen Cell Mill (RHO Scientific, Commack, New York, U.S.A.). After removing the beads by filtration on a coarse glass sinter, walls were isolated by differential centrifugation $\left(16316 \mathrm{~g}, 10 \mathrm{~min}, 4^{\circ} \mathrm{C}\right)$ and washed once in cold water. Walls were heated in boiling water for $15 \mathrm{~min}$ to inactivate autolytic enzymes and were further purified by nuclease and trypsin treatments and by phenol extraction to remove lipoteichoic acid (Schliefer \& Kocur, 1973). Finally, the walls were washed extensively in water.

The teichoic acid type was determined by extraction of walls with $2 \mathrm{M}-\mathrm{HCl}$ at room temperature for $24 \mathrm{~h}$ followed by hydrolysis and alkaline phosphatase treatment of the extract (Wolin, Archibald \& Baddiley, 1966; Schliefer \& Kocur, 1973). Both untreated and alkaline phosphatase-treated hydrolysates were examined by paper chromatography in solvent systems A and C of Wolin et al. (1966) and 1-butanol/pyridine/water (6:4:3, by vol.). Reducing compounds were visualized by the alkaline silver nitrate reagent (Trevelyan, Procter \& Harrison, 1950) and amino compounds by ninhydrin treatment $\left[0 \cdot 25 \%(\mathrm{w} / \mathrm{v})\right.$ in acetone, $100{ }^{\circ} \mathrm{C}$, $5 \mathrm{~min}]$.

The peptidoglycan composition was determined by hydrolysing walls in $6 \mathrm{M}-\mathrm{HCl}$ for $18 \mathrm{~h}$ at $105^{\circ} \mathrm{C}$ and measuring the amino sugars and acids on a Beckman model 120B amino acid analyser (Beckman Instruments, Palo Alto, California, U.S.A.), modified to give better separation of wall components.

Enterotoxin production. Enterotoxin A to E production was assayed serologically. Organisms were grown in BHI broth with shaking for $24 \mathrm{~h}$ and $25 \mathrm{ml}$ were dialysed against polyethylene glycol and lyophilized. Dried preparations were reconstituted with $0.5 \mathrm{ml}$ sterile saline and assayed for enterotoxin by a microslide gel diffusion method (Casman et al., 1969). 
Table 2. Growth characteristics and antibiotic resistance of coagulase-negative, heat-stable nuclease-positive staphylococcal strains

\begin{tabular}{|c|c|c|c|c|c|}
\hline Strair: & $\begin{array}{c}\text { Colony } \\
\text { diam. (mm) }\end{array}$ & $\begin{array}{c}\text { Salt } \\
\text { tolerated (\%) }\end{array}$ & $\begin{array}{l}\text { Growth } \\
\text { at } 45^{\circ} \mathrm{C}\end{array}$ & $\begin{array}{c}\text { Anaerobic } \\
\text { growth in } \\
\text { thioglycollate* }\end{array}$ & $\begin{array}{l}\text { Antibiotic } \\
\text { resistance } \dagger\end{array}$ \\
\hline RB-8 & $4 \cdot 25$ & 10 & + & \pm & None \\
\hline RB-11 & $6 \cdot 0$ & 10 & + & $\bar{t}$ & None \\
\hline FB-1 & $6 \cdot 5$ & 10 & + & + & Pen, Tet \\
\hline FB-2 & $1 \cdot 5$ & 10 & - & - & Tet \\
\hline ML-26 & $6 \cdot 25$ & 10 & + & + & Tet \\
\hline ML-55 & $5 \cdot 0$ & 10 & + & + & Ery \\
\hline LH-A3 & $3 \cdot 5$ & 10 & + & $\pm c$ & Pen (I) \\
\hline LH-A12 & 5.0 & 10 & + & + & Tet (I) \\
\hline FDA-R 75 & $4 \cdot 5$ & 10 & + & + & None \\
\hline $\mathrm{TPC}-1$ & $5 \cdot 0$ & 15 & - & - & Nov, Pen (I) \\
\hline TPC-2 & $5 \cdot 0$ & 15 & - & - & Nov, Pen (I) \\
\hline TPC-3 & $3 \cdot 0$ & 15 & + & + & None \\
\hline TPC-Armour & $3 \cdot 0$ & 10 & + & + & None \\
\hline
\end{tabular}

* Symbols for anaerobic growth: + , dense, uniform; \pm , gradient of dense to light growth; $\pm \mathrm{c}$, gradient plus large individual colonies; - , no growth anaerobically (Kloos \& Schliefer, 1975b).

$\dagger$ Abbreviations: Pen, penicillin G; Tet, tetracycline; Ery, erythromycin; Nov, novobiocin; I, intermediate.

Protein $A$ estimation. This was tested using a haemagglutination assay with sensitized sheep red blood cells (Winblad \& Ericson, 1973) as described by Peterson et al. (1977).

Antibiotic susceptibilities. These were determined according to the method of Bauer et al.i (1966); zone diameter was measured after $24 \mathrm{~h}$ incubation. The following antibiotics (BBL) were used (disc potency in parentheses): cephalothin $(30 \mu \mathrm{g})$, clindamycin $(2 \mu \mathrm{g})$, erythromycin $(15 \mu \mathrm{g})$, gentamicin $(10 \mu \mathrm{g})$, methicillin $(5 \mu \mathrm{g})$, nafcillin $(1 \mu \mathrm{g})$, novobiocin $(30 \mu \mathrm{g})$, penicillin $\mathrm{G}(10 \mathrm{units})$, tetracyline $(30 \mu \mathrm{g})$ and vancomycin $(30 \mu \mathrm{g})$. The zone diameters were interpreted as sensitive, intermediate or resistant according to the chart supplied by the manufacturers.

Phage typing. Organisms were typed at routine test dilution (RTD) and 100 RTD using the international set of human $S$. aureus phages by the method of Blair \& Williams (1961). The organisms were also tested at RTD with the S. epidermidis phage set of Verhoef, Van Boven \& Winkler (1971).

Materials. Deoxyribonuclease I (EC 3.1.4.5, 2588 units $\mathrm{mg}^{-1}$ ), ribonuclease I (EC 3.1.4.22, 2500 units $\mathrm{mg}^{-1}$ ) and trypsin (EC 3.4.21.4, 189 units $\mathrm{mg}^{-1}$ ) were purchased from Worthington Biochemical Corporation. Lysostaphin (210 units $\mathrm{mg}^{-1}$ ) was purchased from Schwarz/Mann, Orangeburg, New York, U.S.A. Alkaline phosphatase from calf intestinal mucosa, type I (EC 3.1.3.1, 1 1 units $\mathrm{mg}^{-1}$ ) and Soybean Trypsin Inhibitor type 1-S were purchased from Sigma.

\section{RESULTS}

\section{Identification as Micrococcaceae}

The test strains were classified in the family Micrococcaceae, being non-motile, Grampositive cocci, approx. $1 \mu \mathrm{m}$ in diam., and dividing in uneven planes to form irregular clusters. All were catalase- and benzidine-positive and oxidase-negative.

\section{Identification as staphylococci}

The organisms were identified as belonging to the genus Staphylococcus. They fermented glucose (except FB-2) and were susceptible to lysostaphin but resistant to lysozyme. All strains contained teichoic acids in the cell wall and had peptidoglycans with large amounts of glycine (Table 5). In addition, all tolerated at least $10 \%(\mathrm{w} / \mathrm{v}) \mathrm{NaCl}$ and most grew at $45^{\circ} \mathrm{C}$ (Table 2).

\section{Characterization of strains}

Most of the organisms failed to coagulate rabbit, human or pig plasmas with the exception of strains RB-8 and FDA-R75 which gave weak reactions in pig plasma (Table 3). Growth 
Table 3. Enzymic activities of coagulase-negative, heat-stable nuclease-positive staphylococcal strains

\begin{tabular}{|c|c|c|c|c|c|c|c|c|c|}
\hline \multirow[b]{2}{*}{ Strain } & \multicolumn{3}{|c|}{ Coagulase* } & \multicolumn{2}{|c|}{$\begin{array}{c}\text { Heat-stable } \\
\text { nuclease } \dagger\end{array}$} & \multirow{2}{*}{$\begin{array}{l}\text { Nitrate } \\
\text { reductase }\end{array}$} & \multirow{2}{*}{$\begin{array}{l}\text { Phos- } \\
\text { phatase }\end{array}$} & \multirow{2}{*}{$\begin{array}{l}\text { 'Lyso- } \\
\text { zyme' } \\
\text { produc- } \\
\text { tion }\end{array}$} & \multirow{2}{*}{ Tellurite } \\
\hline & $\mathbf{H}$ & $\mathbf{R}$ & $\mathbf{P}$ & Static & Aerobic & & & & \\
\hline RB-8 & NT & $2+$ & $3+$ & $1 \cdot 5$ & 0.0 & + & - & w & w \\
\hline RB-11 & 0 & $1+$ & $1+$ & $0 \cdot 0$ & $1 \cdot 5$ & + & + & + & + \\
\hline FB-1 & 0 & $2+$ & $1+$ & 0.7 & $0 \cdot 8$ & + & + & + & w \\
\hline FB-2 & $1+$ & $2+$ & $1+$ & $0 \cdot 0$ & $1 \cdot 9$ & + & - & - & $\mathrm{w}$ \\
\hline ML-26 & NT & $2+$ & 0 & $1 \cdot 0$ & $2 \cdot 6$ & + & + & + & w \\
\hline ML-55 & 0 & $2+$ & $1+$ & 0.8 & $2 \cdot 9$ & + & + & + & w \\
\hline LH-A 3 & 0 & $2+$ & $1+$ & 0.0 & $1 \cdot 8$ & + & - & - & w \\
\hline LH-A12 & 0 & $2+$ & $1+$ & 1.9 & $3 \cdot 0$ & + & + & + & + \\
\hline FDA-R 75 & NT & $2+$ & $3+$ & $4 \cdot 6$ & $7 \cdot 3$ & + & + & + & w \\
\hline TPC-1 & $1+$ & $1+$ & 0 & 0.7 & $2 \cdot 2$ & + & + & + & + \\
\hline TPC-2 & NT & $1+$ & 0 & 0.0 & $1 \cdot 7$ & + & + & + & + \\
\hline TPC-3 & $1+$ & $2+$ & 0 & $1 \cdot 3$ & $2 \cdot 6$ & + & + & + & + \\
\hline TPC-Armour & 0 & $1+$ & 0 & $2 \cdot 4$ & $3 \cdot 0$ & + & + & + & + \\
\hline
\end{tabular}

NT, Not tested; w, weak reaction.

* Human (H), rabbit (R) and porcine (P) plasmas were used. Results are for statically grown cultures read after $4 \mathrm{~h}$, scored as 0 to $4+$.

$\dagger$ Value refers to zone diameter $(\mathrm{mm})$ minus well diameter $(2 \mathrm{~mm})$ after $4 \mathrm{~h}$ incubation. Organisms were grown statically or with shaking (aerobic).

under aerobic conditions did not lead to increased coagulase activity. The test strains also failed to coagulate rabbit plasma when the inoculum was taken from a blood agar plate as recommended by the International Subcommittee (1965). In addition, all organisms failed to produce fibrinolysin, indicating that the coagulase reactions observed were indeed negative and not due to the dissolution of clots already formed. The organisms were negative for clumping factor.

The test strains produced both a heat-labile and heat-stable deoxyribonuclease, and generally aerobic growth led to detection of increased activity (Table 3). Interestingly, strain RB-8 produced less heat-stable nuclease when grown aerobically. The reactions observed were weak when compared to those of typical $S$. aureus strains, which demonstrate zone diameters of 1 to $3 \mathrm{~cm}$ according to Sperber \& Tatini (1975). The reactions were verified by the method of Barry et al. (1973) which uses about a $2 \cdot 5$-fold larger sample. All preparations, both statically and aerobically grown, gave stronger positive reactions.

Based on the results of the coagulase and nuclease tests, the organisms cannot be classified with any of the currently recognized staphylococcal species ( $S$. aureus, S. epidermidis and $S$. saprophyticus). Additional tests were therefore carried out which revealed the organisms to be a heterogeneous group. These tests were growth characteristics (Table 2), the determination of several enzyme activities (Table 3), carbohydrate utilization patterns (Table 4) and wall composition (Table 5).

In other tests none of the organisms appeared to contain protein A (strain FB-1 gave an equivocal result) or produce enterotoxins. An inhibition reaction was observed between strain FDA-R 75 and phage 77, at 100 RTD, of the human international $S$. aureus set. This strain gave weak reactions with the $S$. epidermidis phages 82 and 275 B and strain TPC-3 gave weak reactions with phages 41 and 130. The most striking aspect of the antibiotic resistance patterns (Table 2) was the novobiocin resistance of two strains.

\section{Identification of species}

Staphylococcus aureus - strains FDA-R75 and FB-1. These organisms appear to be coagulase-negative $S$. aureus strains as they showed a positive correlation in all of the following 


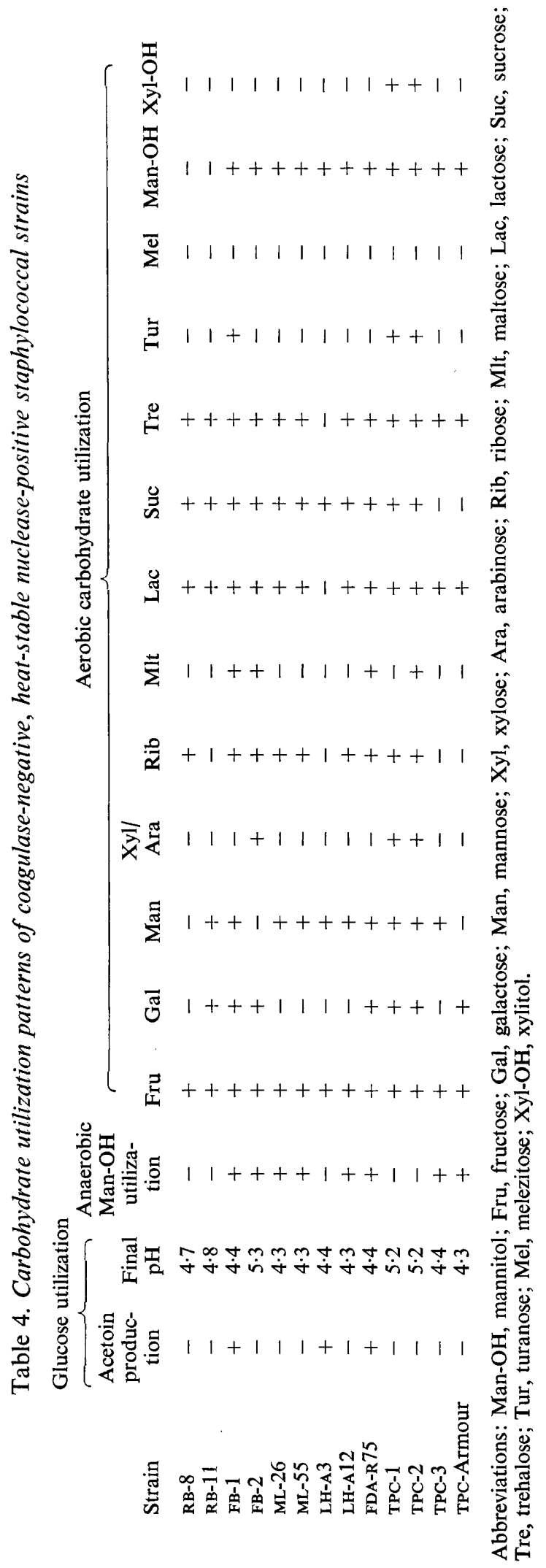




\section{Table 5. Wall composition of coagulase-negative, heat-stable nuclease-positive staphylococcal strains}

\begin{tabular}{|c|c|c|c|c|c|c|c|c|c|}
\hline \multirow[b]{2}{*}{ Strain } & \multirow{2}{*}{$\begin{array}{l}\text { Teichoic acid type } \\
\text { and substituent }\end{array}$} & \multicolumn{8}{|c|}{ Molar ratios of components in cell wall hydrolysates } \\
\hline & & Ser & Mur & Glu & Gly & Ala & $\mathrm{GlcNH}_{2}$ & Lys & $\mathrm{GalNH}_{2}$ \\
\hline RB-8 & Glycerol, $\mathrm{GlcNH}_{2}$ & $0 \cdot 16$ & $0 \cdot 42$ & $1 \cdot 0$ & $5 \cdot 7$ & $2 \cdot 8$ & $1 \cdot 7$ & $1 \cdot 0$ & - \\
\hline RB-11 & Glycerol, glucose & $0 \cdot 33$ & 0.38 & $1 \cdot 0$ & $4 \cdot 6$ & $2 \cdot 5$ & 0.75 & 0.96 & - \\
\hline FB-1 & Ribitol, $\mathrm{GlcNH}_{2}$ & 0.04 & $0 \cdot 50$ & 1.0 & $5 \cdot 2$ & $2 \cdot 3$ & $1 \cdot 3$ & $1 \cdot 1$ & - \\
\hline FB-2 & Glycerol, $\mathrm{GlcNH}_{2}$ & 0.02 & 0.45 & $1 \cdot 0$ & 4.9 & $3 \cdot 4$ & $1 \cdot 7$ & $1 \cdot 1$ & - \\
\hline$M L-26$ & Glycerol, GalNH & 0.06 & 0.43 & $1 \cdot 0$ & $5 \cdot 4$ & $2 \cdot 1$ & 0.81 & 0.94 & $0 \cdot 35$ \\
\hline ML-55 & Glycerol, $\mathrm{GalNH}_{2}$ & 0.05 & 0.40 & $1 \cdot 0$ & $5 \cdot 1$ & $2 \cdot 5$ & $1 \cdot 0$ & $1 \cdot 0$ & $0 \cdot 21$ \\
\hline LH-A 3 & Glycerol & $1 \cdot 2$ & 0.39 & $1 \cdot 0$ & $4 \cdot 4$ & $2 \cdot 3$ & 0.93 & $1 \cdot 1$ & - \\
\hline LH-A12 & Glycerol, GalNH & 0.05 & 0.49 & $1 \cdot 0$ & $5 \cdot 7$ & $2 \cdot 2$ & 0.94 & $1 \cdot 0$ & $0 \cdot 33$ \\
\hline FDA-R 75 & Ribitol, $\mathrm{GlcNH}_{2}$ & 0.02 & 0.42 & $1 \cdot 0$ & $5 \cdot 6$ & $2 \cdot 5$ & $1 \cdot 3$ & $1 \cdot 0$ & - \\
\hline TPC-1 & Ribitol, GlcNH & 0.03 & 0.45 & $1 \cdot 0$ & $5 \cdot 5$ & $2 \cdot 5$ & $2 \cdot 0$ & $1 \cdot 0$ & - \\
\hline TPC-2 & Ribitol, GlcNH & 0.08 & 0.41 & $1 \cdot 0$ & $5 \cdot 3$ & $2 \cdot 7$ & $1 \cdot 8$ & $1 \cdot 0$ & - \\
\hline TPC-3 & Glycerol, GlcNH & 0.07 & $0 \cdot 36$ & $1 \cdot 0$ & $5 \cdot 5$ & $2 \cdot 0$ & $1 \cdot 5$ & $1 \cdot 0$ & - \\
\hline TPC-Armour & Ribitol & 0.04 & 0.43 & 1.0 & $5 \cdot 4$ & $2 \cdot 1$ & 0.89 & 1.0 & - \\
\hline
\end{tabular}

Abbreviations: Ser, serine; Mur, muramic acid; Glu, glutamic acid; Gly, glycine; Ala, alanine; $\mathrm{GICNH}_{2}$, glucosamine; Lys, lysine; GalNH ${ }_{2}$, galactosamine.

characteristics with bona fide $S$. aureus strains: heat-stable nuclease production, ribitolglucosamine teichoic acid, peptidoglycan type, nitrate reductase and phosphatase activities, colony characteristics, growth at $45^{\circ} \mathrm{C}$, acetoin production, final $\mathrm{pH}$ in glucose broth, anaerobic mannitol utilization, aerobic carbohydrate utilization patterns and production of bacteriolytic activity. In addition, FDA-R75 gave an inhibition reaction with a human $S$. aureus phage. Besides coagulase production, the organisms failed to correlate with $S$. aureus in not being haemolytic and in not growing in the presence of $15 \%$ salt. One of the organisms (FDA-R75) came from the nose/throat of a healthy human, the other (FB-1) from a turkey bone.

Staphylococcus xylosus - strains TPC-1 and TPC-2. These organisms correlated in almost all characteristics with the description of $S$. xylosus given by Schliefer \& Kloos (1975) but were strongly bacteriolytic. These characteristics included production of acid from xylose, utilization of a wide range of sugars, novobiocin resistance, ribitol-glucosamine teichoic acid and peptidoglycan type. The organisms produced very distinctive large, white and gold colonies with crenate edges, failed to grow at $45^{\circ} \mathrm{C}$, tolerated $15 \%$ salt, did not grow in thioglycollate or produce acetoin, and gave a final $\mathrm{pH}$ of above 5 in glucose broth. Nitrate reductase and phosphatase activities were detected but acid was not formed from mannitol anaerobically. The organisms were isolated from wholesome food.

Staphylococcus simulans - strains ML-26, ML-55 and LH-A12. These strains were isolated from human urine and showed excellent correlation with the description of $S$. simulans given by Kloos \& Schliefer $(1975 a$ ). The organisms had a glycerol-galactosamine teichoic acid and a low serine/high glycine peptidoglycan. Dense growth in thioglycollate was shown, large colonies were produced, several sugars were utilized including ribose, acetoin was not formed but bacteriolytic activity, nitrate reductase and phosphatase activities were all shown. The final $\mathrm{pH}$ in glucose broth was lower than described by Kloos \& Schliefer $(1975 a)$. The organisms produced acid from mannitol anaerobically.

Staphylococcus sciuri subsp. lentus - strain FB-2. In terms of enzymic activities, carbohydrate utilization and growth tests this organism resembled $S$. xylosus strains TPC-1 and TPC-2. However, the organism had a glycerol-glucosamine teichoic acid and, notably, a high alanine content in the wall which is typical of $S$. sciuri (Kloos et al., 1976). The organism appeared to belong to the lentus subspecies on the basis of small colony diameter, 
failure to grow at $45^{\circ} \mathrm{C}$, absence of phosphatase activity and lack of bacteriolytic activity. Nitrate was reduced, acid was produced from galactose, glycerol and lactose, the final $\mathrm{pH}$ in glucose broth was over 5 and mannitol was fermented anaerobically. The organism was isolated from a turkey joint.

Staphylococcus capitis - strain LH-A3. This strain correlated with S. capitis (Kloos \& Schliefer, 1975a) in the following characteristics: small white colonies, growth in aerobic and anaerobic portion of thioglycollate medium, final $\mathrm{pH}$ in glucose broth, failure to grow in $15 \%$ salt, growth at $45^{\circ} \mathrm{C}$ and lack of phosphatase activity. Only a few carbohydrates were utilized, acid was produced from mannitol but not from trehalose or lactose, properties consistent with the identification as $S$. capitis. The high serine content of the peptidoglycan correlated with $S$. capitis as did the wall teichoic acid in that it was a glycerol type with no additional sugar constituent identified. However, excess glutamic acid was not found in the wall and the organism was not bacteriolytic, both of which are properties of $S$. capitis. The organism did not utilize mannitol anaerobically. The organism was isolated from human urine.

\section{Unidentified organisms}

It was not possible to identify the remaining strains. They were isolated from veterinary sources (strains RB-8 and RB-11) and from food (strains TPC-3 and TPC-Armour). Strain RB-11, which was isolated from feline urine, had a glucose-containing glycerol teichoic acid and a high serine content in its peptidoglycan. These attributes are typical of $S$. epidermidis but, unlike strains of the latter, the organisms did not produce large colonies or acetoin, and produced acid from trehalose but not from maltose. Strain RB-8, isolated from an equine hock joint, had a glycerol-glucosamine teichoic acid and a high serine content in its peptidoglycan. Strains RB-8 and RB-11 did not coagulate rabbit plasma or produce acid anaerobically from mannitol and could thereby be distinguished from the newly proposed Staphylococcus intermedius species from animals (Hájek, 1976).

Strain TPC-3, isolated from wholesome food, correlates best with $S$. simulans in growth characteristics, enzymic activities and carbohydrate utilization patterns. However, the organism has a glucosamine rather than galactosamine-containing glycerol teichoic acid, but does have a low serine/high glycine peptidoglycan. It is possible this organism represents a variety of $S$. simulans. Strain TPC-Armour, also isolated from food, has some unusual features and may represent an as yet undescribed species. The organism has an unsubstituted ribitol teichoic acid and a low serine/high glycine peptidoglycan. The organism does not appear to be a strain of $S$. aureus as it fails to produce acetoin and does not produce acid aerobically from several sugars including sucrose. Kloos et al. (1976) have found strains of at least two species, isolated from the skin of various mammals, that fail to produce acid from sucrose.

Specific identification of these four strains will presumably have to await extension of the host range in staphylococcal classification. Strain TPC-Armour in particular has quite distinctive properties and may represent a distinct species.

\section{DISCUSSION}

Previous workers who have studied coagulase-negative, heat-stable deoxyribonuclease staphylococci have had difficulty in conclusively identifying their organisms as any of the presently accepted species ( $S$. aureus, $S$. epidermidis and $S$. saprophyticus). Here, of 13 of these strains examined, two were coagulase-negative $S$. aureus strains. Seven of the strains were identified as $S$. xylosus (2), S. simulans (3), S. capitis (1) and S. sciuri subsp. lentus (1) (Kloos et al., 1976). The remaining four organisms were not identified at the species level. Such a heterogeneous collection of species may be due, in part, to the varied origins of the test strains.

Coagulase-negative $S$. aureus strains have been noted occasionally (Kapral \& Li, 1960; 
Lominski, Smith \& Morrison, 1953). Dobrin et al. (1975), on the basis of serological tests, described two coagulase-negative staphylococci in renal infections that contained ribitol teichoic acids. As ribitol teichoic acid is a good indicator of $S$. aureus it is possible that these pathogens were of this species. From our results it seems possible that heat-stable deoxyribonuclease determinations can serve to detect coagulase-negative $S$. aureus strains. Interestingly, Hájek \& Maršálek (1976) reported that four of 50 S. epidermidis strains produced heat-stable deoxyribonuclease and that three of 50 strains contained ribitol teichoic acids. These authors did not say whether the organisms corresponded in the two tests but it may be that some of these organisms were coagulase-negative $S$. aureus strains.

However, our results show that heat-stable deoxyribonuclease activity is not confined to $S$. aureus. Kloos \& Schliefer (1975a), Kloos, Schliefer \& Smith (1976) and Schliefer \& Kloos (1975) have reported that $S$. simulans, $S$. sciuri, $S$. capitis and some members of $S$. xylosus possess weak or moderate deoxyribonuclease activity, but they did not report on the heat stability of the enzyme activities. It would be useful to know whether weak, heat-stable deoxyribonuclease activity was typical of all members of these species, or whether the organisms we describe represent unusual cases. In the present study, $S$. epidermidis and $S$. saprophyticus were amongst the coagulase-negative species not encountered, but the significance of these observations will have to await further detailed studies of coagulase-negative, heat-stable deoxyribonuclease-positive organisms. Four of the organisms studied could not be identified as any accepted or newly proposed species. These organisms were from food and veterinary sources and their identification must await extension of species characterization to organisms from these sources and the willingness of investigators to continually refine staphylococcal classification.

In a study of coagulase-negative heat-stable nuclease-positive staphylococci from human sources, Dornbusch et al. (1976) concluded that the organisms belonged to a heterogeneous intermediate group sharing characteristics of $S$. aureus and $S$. epidermidis. Smith \& FarkasHinsley (1969) studied 21 pathogenic, coagulase-negative staphylococci and concluded that strains within the genus formed a continuous spectrum between the two extremes of $S$. aureus and $S$. epidermidis. Clearly, the recent refinement of classification of coagulasenegative staphylococci (Kloos et al., 1976) allows for more specific identification of intermediate organisms. For example, the organisms of human origin in this study have been identified as $S$. aureus, $S$. simulans and $S$. capitis.

Currently, there is appreciable interest in coagulase-negative staphylococci as agents of infectious disease. In our study, three $S$. simulans strains were isolated from human urinary tract infections. This species was only rarely encountered by Kloos \& Schliefer $(1975 a)$ who considered the organism to be related to $S$. aureus, which is well known for its potential pathogenicity. Recent studies have been designed to evaluate the role of members of the various coagulase-negative species in causing disease. In a study of 522 coagulase-negative organisms from human infections, Nord et al. (1976) reported that $S$. epidermidis and $S$. saprophyticus were most commonly isolated (together $69 \%$ ) although, with the exception of $S$. xylosus and $S$. sciuri, all of the new coagulase-negative species were encountered. Recently, Oeding \& Digranes (1977) reported that a considerable number of infections were caused by coagulase-negative species other than $S$. epidermidis and $S$. saprophyticus. However, more studies of the relationship between disease and the new coagulase-negative staphylococcal species would seem to be warranted.

We are grateful to Kathy Holmes and Margaret Munyan for their diligent technical assistance, to Dr Sita R. Tatini for enterotoxin determinations and to David Peterson for amino acid analysis. We thank Dr Jan Verhoef for attempting to phage-type the organisms with his $S$. epidermidis set. This work was supported, in part, by a Grant-in-Aid from the University of Minnesota Graduate School (to B.J.W.). We are grateful to Dr Leon D. Sabath for his support. 


\section{REFERENCES}

Baird-PARKer, A. C. (1963). A classification of micrococci and staphylococci based on physiological and biochemical tests. Journal of General Microbiology 30, 409-427.

BAIRD-PARKER, A. C. (1974). Staphylococcus Rosenbach 1884. In Bergey's Manual of Determinative Bacteriology, 8th edn. Edited by R. E. Buchanan and N. E. Gibbons. Baltimore: Williams \& Wilkins.

BARRITT, M. M. (1936). The intensification of the Voges-Proskauer reaction by the addition of

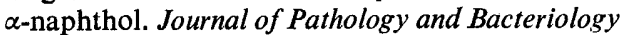
42, 441-454.

BARRY, A. L., LACHICA, R. V. F. \& Atchison, F. W. (1973). Identification of Staphylococcus aureus by simultaneous use of tube coagulase and thermonuclease tests. Applied Microbiology 25, 496-497.

Bauer, A. W., Kirby, W. M., Sherris, J. C. \& TURCK, M. (1966). Antibiotic susceptibility testing by a standardized single disc method. American Journal of Clinical Pathology 45, 493-496.

Blair, J. E. \& Williams, R. E. O. (1961). Phage typing of staphylococci. Bulletin of the World Health Organization 24, 771-784.

Casman, E. P., Bennett, R. W., Dorsey, A. E. \& STONE, J. E. (1969). The microslide double diffusion test for the detection and assay of staphylococcal enterotoxins. Health Laboratory Science 6, 185-198.

Cowan, S. T. \& Steel, K. J. (1965). Manual for the Identification of Medical Bacteria. New York \& London: Cambridge University Press.

Deibel, R. H. \& Evans, J. B. (1960). Modified benzidine test for the detection of cytochromecontaining respiratory systems in microorganisms. Journal of Bacteriology 79, 356-360.

Dobrin, R. S., DAY, N. K., QuiE, P. G., Moore, H. L., Vernier, R. L., Michael, A. F. \& Fish, A. J. (1975). The role of complement, immunoglobulin and bacterial antigen in coagulase-negative staphylococcal shunt nephritis. American Journal of Medicine 59, 660-673.

Dornbusch, K., Nord, C. E., Olsson, B. \& WaDSTRÖM, T. (1976). Some properties of coagulasenegative deoxyribonuclease-producing strains of staphylococci from human infections. Medical Microbiology and Immunology 162, 143-152.

Evans, J. B. \& Kloos, W. E. (1972). Use of shake cultures in a semisolid thioglycollate medium for differentiating staphylococci from micrococci. Applied Microbiology 23, 326-331.

HÁJEK, V. (1976). Staphylococcus intermedius, a new species isolated from animals. International Journal of Systematic Bacteriology 26, 401-408.

HÁJEK, V. \& MARŠÁLEK, E. (1971). The differentiation of pathogenic staphylococci and a suggestion for their taxonomic classification. Zentralblatt für Bakteriologie, Parasitenkunde, Infektionskrankheiten und Hygiene (Abteilung I, Originale A) 217, 176-182.

HÁJEK, V. \& MARŠÁLEK, E. (1976). Evaluation of classificatory criteria for staphyloccoci. In Staphylococci and Staphylococcal Diseases, Proceedings of IIIrd International Symposium on Staphylococci and Staphylococcal Infections, pp. 11-21. Edited by J. Jeljaszewicz. New York: Gustav Fischer Verlag.

Hinton, M. A. \& ORR, J. H. (1957). The distribution of toxins in coagulase-positive staphylococci isolated from infections and carriers. Journal of Laboratory and Clinical Medicine 50, 901-912.

INTERNATIONAL SUBCOMMITTEE ON TAXONOMY OF Staphylococci and Micrococci (1965). Recommendations. International Bulletin of Bacteriological Nomenclature and Taxonomy 15, 109_ 110.

INTERNATIONAL SUBCOMMITTEE ON TAXONOMY OF STAPHYLOCOCCI AND MicRococCI (1976). Appendix I. International Journal of Systematic Bacteriology 26, 332-333.

JASPER, D. E. (1973). Thermostable nuclease production by staphylococci in milk samples from bovine mastitis. American Journal of Veterinary Research 34, 445-446.

KAPRAL, F. A. \& LI, W. I. (1960). Virulence and coagulases of Staphylococcus aureus. Proceedings of the Society for Experimental Biology and Medicine 104, 151-153.

Kloos, W. E. \& Schliefer, K. H. (1975a). Isolation and characterization of staphylococci from human skin. II. Description of four new species: Staphylococcus warnerii, Staphylococcus capitis, Staphylococcus hominis, and Staphylococcus simulans. International Journal of Systematic Bacterio$\log y$ 25, 62-79.

Kloos, W. E. \& SCHLIEFER, K. H. (1975b). Simplified scheme for routine identification of human Staphylococcus species. Journal of Clinical Microbiology 1, 82-88.

Kloos, W. E., Tornabene, T. G. \& Schliefer, K. H. (1974). Isolation and characterization of micrococci from human skin, including two new species: Micrococcus lylae and Micrococcus kristinae. International Journal of Systematic Bacteriology 24, 79-101.

Kloos, W. E., Schliefer, K. H. \& Noble, W. C. (1976). Estimation of character parameters in coagulase-negative Staphylococcus species. In Staphylococci and Staphylococcal Diseases, Proceedings of IIIrd International Symposium on Staphylococci and Staphylococcal Infections, pp. 23-41. Edited by J. Jeljaszewicz. New York: Gustav Fischer Verlag.

Kloos, W. E., Schliefer, K. H. \& SMith, F. R. (1976). Characterization of Staphylococcus sciuri sp. nov. and its subspecies. International Journal of Systematic Bacteriology 26, 22-37.

Kovacs, N. (1956). Identification of Pseudomonas pyocyanea by the oxidase reaction. Nature, London 178, 703.

LaChicha, R. V. F., Genigeorgis, C. \& Hoepich, P. D. (1971). Metachromatic agar-diffusion methods for detecting staphylococcal nuclease activity. Applied Microbiology 21, 585-587. 
Lominski, I., Smith, D. D. \& Morrison, R. B. (1953). A coagulase-destroying factor produced by variants of Staphylococcus aureus. Nature, London 171, 214.

LotTer, L. P. \& Genigeorgis, C. A. (1975). Deoxyribonucleic acid base composition and biochemical properties of certain coagulase-negative enterotoxigenic cocci. Applied Microbiology 29, 152-158.

NoRD, C.-E., Holta-ÖIE, S., LJunGH, A. \& WADSTRÖM, T. (1976). Characterization of coagulasenegative staphyloccocal species from human infection. In Staphylococci and Staphylococcal Diseases, Proceedings of IIIrd International Symposium on Staphylococci and Staphylococcal Infections, pp. 106-111. Edited by J. Jeljaszewicz. New York: Gustav Fischer Verlag.

Oeding, P. \& Digranes, A. (1977). Classification of coagulase-negative staphylococci in the diagnostic laboratory. Acta pathologica et microbiologica scandinavica B85, 136-142.

Pennock, C. A. \& Huddy, R. B. (1967). Phosphatase reaction of coagulase-negative staphylococci and micrococci. Journal of Pathology and Bacteriology 93, 685-688.

Peterson, P. K., Verhoef, J., Sabath, L. D. \& QuiE, P. G. (1977). Effect of protein A on staphylococcal opsonization. Infection and Immunity 15, 760-764.

Rayman, M. K., Park, C. E., Philpott, J. \& Todd, E. C. D. (1975). Reassessment of the coagulase and thermostable nuclease tests as a means of identifying Staphylococcus aureus. Applied Microbiology 29, 451-454.

Salton, M. R. J. \& Freer, J. H. (1965). Composition of the membranes isolated from several gram positive bacteria. Biochimica et biophysica acta 107, 531-538.

Schliefer, K. H. \& Kloos, W. E. (1975). Isolation and characterization of staphylococci from human skin. I. Amended descriptions of Staphylococcus epidermidis and Staphylococcus saprophyticus and descriptions of three new species: Staphylococcus cohnii, Staphylococcus haemo- lyticus and Staphylococcus xylosus. International Journal of Systematic Bacteriology 25, 50-61.

SCHLIEFER, K. H. \& Kocur, M. (1973). Classification of staphylococci based on chemical and biochemical properties. Archiv für Mikrobiologie 93, 65-85.

Schliefer, K. H., Hammes, W. P. \& Kandler, O. (1976). Effect of endogenous and exogenous factors on the primary structures of bacterial peptidoglycan. Advances in Microbial Physiology 13, 245-293.

Smith, H. \& FARKas-Hinsley, H. (1969). The relationship of pathogenic coagulase-negative staphylococci to Staphylococcus aureus. Canadian Journal of Microbiology 15, 879-890.

SPERBER, W. H. \& TATINI, S. R. (1975). Interpretation of the tube coagulase test in the identification of Staphylococcus aureus. Applied Microbiology 29, 502-505.

Trevelyan, W. E., Procter, D. P. \& Harrison, J. S. (1950). Detection of sugars on paper chromatograms. Nature, London 166, 444-445.

Turner, F. J. \& Schwartz, B. S. (1958). The use of lyophilized human plasma standardized for coagulation factors in the coagulase and fibrinolytic tests. Journal of Laboratory and Clinical Medicine 52, 888-894.

VERHOEF, J., VAN Boven, C. P. A. \& WinkLeR, K. C. (1971). Characters of phages from coagulasenegative staphylococci. Journal of Medical Microbiology 4, 413-424.

Victor, R., Lachicha, F., Weiss, K. F. \& Deibel, R. H. (1969). Relationships among coagulase, enterotoxin and heat-stable deoxyribonuclease production by Staphylococcus aureus. Applied Microbiology 18, 126-127.

Winblad, S. \& Ericson, C. (1973). Sensitised sheep red cells as a reactant for Staphylococcus aureus protein A. Acta pathologica et microbiologica scandinavica B 81, 150-156.

Wolin, M. J., Archibald, A. R. \& Baddiley, J. (1966). Changes in wall teichoic acid resulting from mutation of Staphylococcus aureus. Nature, London 209, 484-486. 